\title{
Effect of Modification of Deck Properties on Suspension Bridges
}

\author{
Jagat Kumar Shrestha \\ Department of Civil Engineering, Pulchowk Campus, Institute of Engineering, Tribhuvan University, Nepal \\ Corresponding author: jagatshrestha@ioe.edu.np
}

Received: Feb. 1, 2016 Revised: March 17, 2016 Accepted: April 14, 2016

\begin{abstract}
Different type of deck configuration has been used for suspension bridge depending upon different design requirements. Changes in deck properties lead to changes in behavior of a suspension bridge. In this study, effect of deck modification of a existing bridge from timber to steel deck is considered. Three dimensional finite element models is developed and analyzed changing the deck material from timber to steel which causes reduction in weight and changes in design parameters. This changes the dynamic behavior of the bridge and affects the performance of bearings. The study has been carried out in real world problem encountered in Mugling Suspension Bridge over Trishuli River in Nepal. The study has come up with conclusions and recommendations to increase mass of deck material and replacement of bearings for better performance.
\end{abstract}

Key words: Suspension bridge, deck properties, dynamic behavior

\section{Introduction}

Suspension bridge is the type of bridge in which the main load bearing parts (hanger ropes) are suspended on the cable. The bridge has been gaining popularity in the world due to its less material consumption and the longest span [2]. Deck is one of the crucial parts of the bridge for all traffic passes through it. In olden days, the deck of the suspension bridges were unstiffened, however, since the behavior of the deck depend upon the ratio of live load to the dead load and the problem to control the aerodynamic stability (the famous Takoma Narrow Bridge failure), these were completely abandoned. In today's world, decks are stiffened [5] to the girder (that's partially fixed to the pylon) to control the unnecessary vibration during movement of vehicles such as box deck, deck with trussed girder, etc. Even timber was much popular (still popular in pedestrian suspension bridges) for deck, however, timber decks need frequent maintenance and replacement causing the problem in traffic management and high maintenance cost. Problem in maintenance of Mugling Bridge [4] in Nepal is one of such example. Changing the deck material by other substitutes like steel, has significant impact in bridge behaviors. Due to the structural properties, steel can withstand same strength with lower thickness as compared to timber thus significant weight-reduction may be achieved but for suspension bridge, addition to the strength of deck and weight-reduction, the response of the bridge is also of great importance which is directly related to the traffic movement and bridge stability. In this study this issue has been investigated in terms of static and dynamic parameters and possible solutions are given. 
The bridge [4] has been rehabilitated in 2011 by replacing the timber deck with the steel deck considering the lightness of the steel deck over the timber deck and replacement of damaged roller bearing at the left support with a new one and anticipated the bridge life extension for next 20 years. However, in January 2014, the bridge showed a vibration, under moving loads, as in pedestrian suspension bridge with failure of the bolts in the gusset plate near to the left end as seen in Fig. 1.

This problem was encountered after timber deck replacement with the steel deck along with deck geometry and the bearing replacement. Hence, this study focuses on the effect of the modification of deck properties on the behavior of the suspension bridge due to the moving loads.

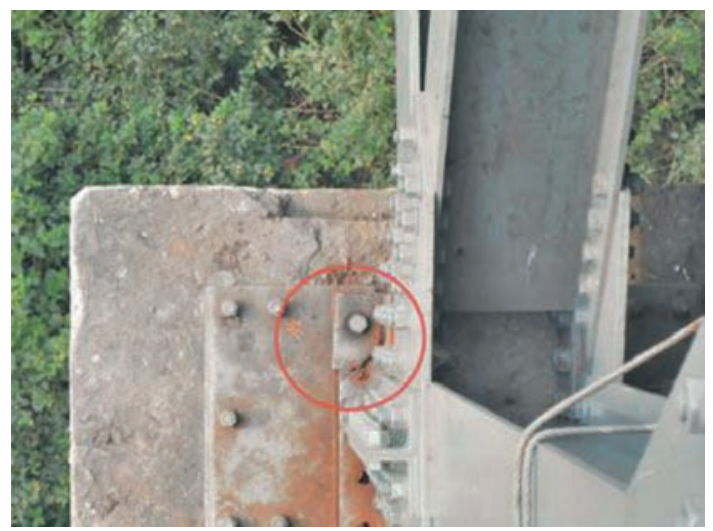

Fig. 1: Failure of the bolts in the gusset plate near to the left end

The main objective of the study is to investigate the effect of modification of deck properties on the behavior of the suspension bridge which considers the static and dynamic behavior of the bridge before and after the replacement of the deck.

This paper presents the outcome of the study as follows: The issue of the study is introduced in Section 1. The deck properties of the Mugling Bridge are described in Section 2. Section 3 presents the analysis and the results of the study. The static and dynamic behaviors along with the time history analysis of the bridge on the different materials are presented in this section. Finally, conclusions of the study are presented in Section 4.

\section{Description of Parts of Mugling Bridge}

Mugling suspension bridge, an important element of Prithvi Highway (Nepal) that links the capital city, Kathmandu with the beautiful tourist city Pokhara, popular for 13 lakes and view of Fishtail Mountain is the first motorable suspension bridge in Nepal with main span length of $124.8 \mathrm{~m}$ was constructed in 1972 under Chinese assistance. The properties of main parts of the bridge are described as below [3].

\subsection{Dimensions of the Bridge}

The main span is suspended by the cables, which are anchored in concrete blocks on either bank. The maximum cable sag is 12.43 and the height of the towers is $14.2 \mathrm{~m}$. The total width of the timber deck is $8.4 \mathrm{~m}$ and the depth of the steel truss is $3.24 \mathrm{~m}$. A sketch of the bridge along with some key dimensions can be seen in Fig. 2. 


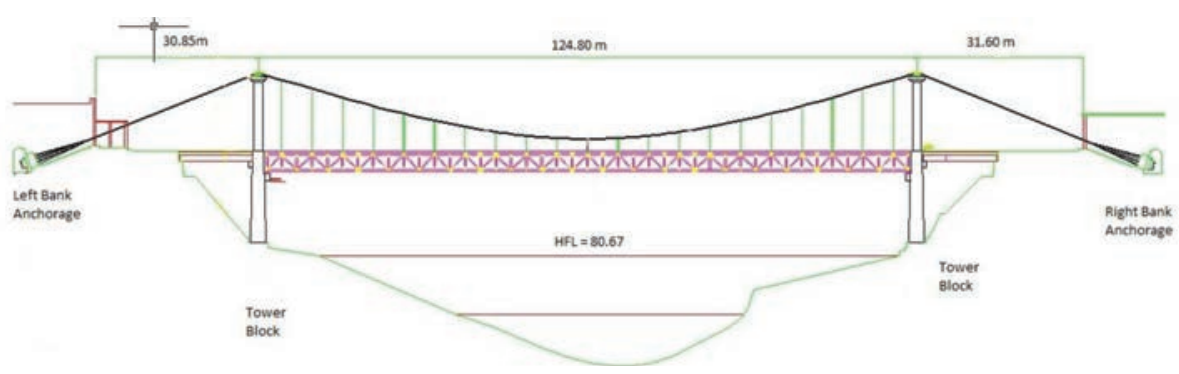

Fig. 2: Schematic Diagram of Mugling Bridge

\subsection{Cables}

There are 19 numbers of $40 \mathrm{~mm}$ diameter cables in each side of carriage way. From surface observation, its construction is Right Hand Ordinary Lay. There are 6 strands around the core. The type of core is not visible. The wire diameter is around $2.5 \mathrm{~mm}$. The pitch of lay is about $28 \mathrm{~cm}$. The wire ropes used in Trail Bridge has 7x19=133 wires (12/6/1) construction and Right Hand Ordinary Lay. It has wire strand core. Tensile strength of wire is $1570 \mathrm{MPa}$.

\subsection{Bridge Deck}

The bridge deck of $8.4 \mathrm{~m}$ width with $1.1 \mathrm{~m}$ footpath on either side was originally made up of timber beam of sizes approximately of $70 \mathrm{~mm} \times 200 \mathrm{~mm}$ linked by steel rod $10 \mathrm{~mm}$ dia. at the spacing of $750 \mathrm{~mm}$ approximately. The timber used was hard Sal wood. The asphalt concrete of $100 \mathrm{~mm}$ thickness was laid over the timber deck as shown in Fig. 3. Later the timber deck was replaced with the $10 \mathrm{~mm}$ thick steel plate deck and the steel stringer made up of ISMB 250 at spacing of $600 \mathrm{~mm}$ considering the lightness as shown in Fig. 4.

\subsection{Stiffening Girder}

The girder is made of truss composed of $300 \times 240 \times 18$ I Section with length $8.1 \mathrm{~m}$ on top supported by diagonal double angle sections $160 \times 100 \times 12$ and $120 \times 80 \times 10$ with length of $3.1 \mathrm{~m}$ and at the bottom by angle $120 \times 80 \times 10$ of length $8.1 \mathrm{~m}$. The trusses are interconnected with one another at the top and bottom by angle sections $160 \times 100 \times 12$ of length $4.7 \mathrm{~m}$. The trusses are supported on the truss spanning along the length of the bridge consisting of I Section $360 \times 300 \times 18$ of length $8.1 \mathrm{~m}$ at the top, vertical member of I Section $303 \times 240 \times 18$ and diagonal member of I Section $160 \times 100 \times 18$. The details of the sections are as tabulated in Table 1, Table 2 and Table 3 below:

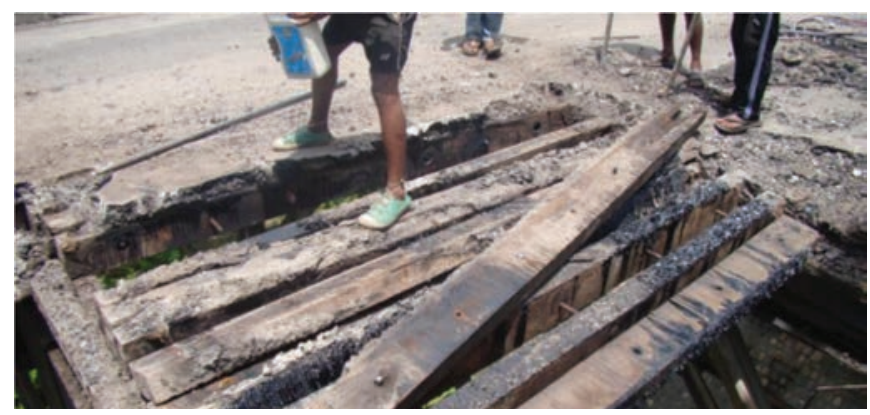

Fig. 3: Dismantling of Timber Deck 


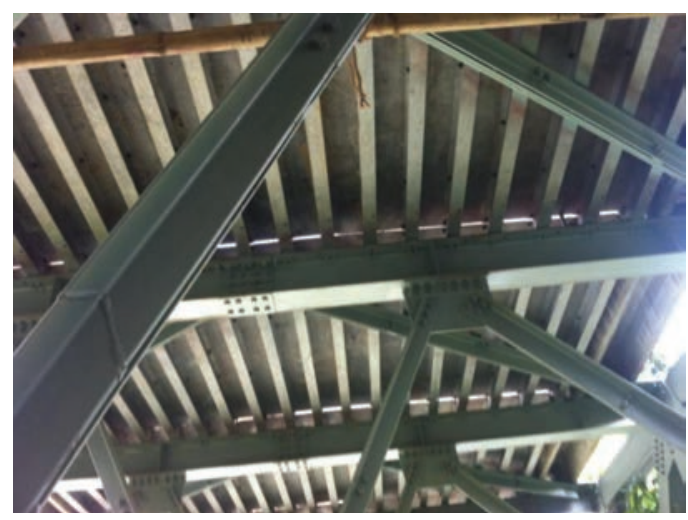

Fig. 4: Steel Deck and Stiffener

Table 1: Sections of Girder

\begin{tabular}{|c|c|c|c|c|c|}
\hline SN & Section & Size & Length, $\mathrm{m}$ & Spacing, $\mathrm{m}$ & Remarks \\
\hline 1 & $\mathrm{I}$ & $360 \times 300 \times 18$ & 8.10 & 2.9 & Top, Outer side \\
\hline 2 & $\mathrm{I}$ & $303 \times 240 \times 18$ & 3.24 & & Vertical, Outer side \\
\hline 3 & $\mathrm{I}$ & $160 \times 100 \times 18$ & 3.35 & & Diagonal, Outer side \\
\hline 4 & $\mathrm{I}$ & $300 \times 240 \times 18$ & 8.10 & 2.9 & \\
\hline 5 & Double Angle & $160 \times 100 \times 12$ & 3.15 & & \\
\hline 6 & Double Angle & $120 \times 80 \times 10$ & 3.15 & & \\
\hline
\end{tabular}

Table 2: Longitudinal I-Girder Sectional Properties

\begin{tabular}{|c|c|c|c|c|c|}
\hline SN & Size & Area, mm2 & IXX, mm4 & IYY, mm4 & Remarks \\
\hline 1 & 360 X 300 X 18 & 6912 & 10231296 & 12319104 & Top, Outer side \\
\hline 2 & 303 X 240 X 18 & 13392 & 199604736 & 41600304 & Vertical, Outer side \\
\hline 3 & 160 X 100 X 18 & 13446 & 204230524.5 & 41601762 & Diagonal, Outer side \\
\hline 4 & 300 X 240 X 18 & 17712 & 285607296 & 140096304 & Across the bridge \\
\hline 5 & ISMB250 & 4755 & 51316001 & 3345000 & $\begin{array}{c}\text { Stringer Beam inserted after } \\
\text { removal of timber deck and } \\
\text { to lay the steel deck }\end{array}$ \\
\hline
\end{tabular}

Table 3: Cross Girder (Double Angle Sections) Properties

\begin{tabular}{|c|c|c|c|c|c|}
\hline SN & Size & Area, mm2 & IXX, mm4 & IYY, mm4 & Remarks \\
\hline 1 & $\begin{array}{c}\text { DA 160 X } \\
120 \times 10\end{array}$ & 4032 & 3900269.714 & 4197376 & $\begin{array}{c}\text { Diagonals in Vertical Plane, } \\
\text { Diagonal Bracing in Lower } \\
\text { \& Upper Horizontal Plane. }\end{array}$ \\
\hline 2 & $\begin{array}{c}\text { DA 80 X 120 } \\
\text { X 10 }\end{array}$ & 2600 & 1615512.821 & 1486666.667 & Diagonals in Vertical Plane \\
\hline
\end{tabular}




\subsection{Pylon}

The pylon as shown in Fig. 5 consists of $1.4 \mathrm{~m} \times 1.6 \mathrm{~m}$ section towers on each road side concrete tower interconnected at top by $1.4 \mathrm{~m}$ X $1.4 \mathrm{~m}$ concrete beam and a cross frame ( in shape of ' $\mathrm{X}$ ') with sizes of $1 \mathrm{~m} \times 0.5 \mathrm{~m}$ and by beam of size $0.5 \mathrm{~m}$ X $0.5 \mathrm{~m}$ below the road level. There are saddles to support rollers that hang the suspension cable on the tower-tops.

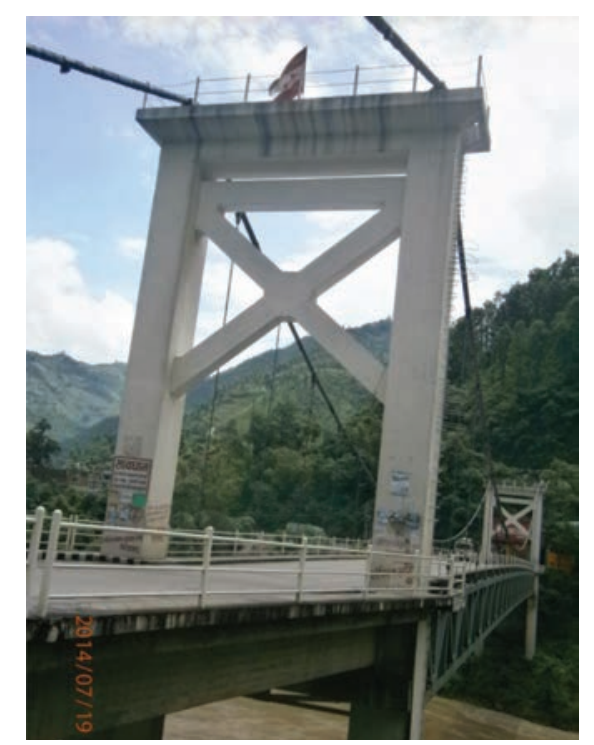

Fig. 5: Pylon

\section{Analysis and Results}

Finite element method being a versatile method of numerical computation and analysis for structural analysis has been used frequently in every field of science and engineering [2]. The method has been used for investigation of the suspension bridge considered for the study. The suspension bridge is highly nonlinear structure due to the behavior of cable as nonlinear. The shape, axial stress all changes with the change in loads which is addressed in terms of nonlinearity, namely geometric and material nonlinearity. The geometric nonlinearity arises when a structure is subjected to such large deformations that considerable alteration occurs in load application and resistance. The material nonlinearity accounts for a nonlinear stress-strain relation in the structural material under applied loading [3].

The suspension bridge being a complex structure with all loads are carried by the suspension cable that transferred to the ground through anchorage and tower hence when in unloaded condition, the dead load of the self-causes the bridge to some deflection. However, any structure should not deflect initially. So prestressed are applied until a stable minimum deflected configuration achieved. This process of getting initial configuration is called the form finding process [8]. This process in the finite element analysis termed as the static analysis and carried out before the live load or dynamic analysis. Starting from the deformed equilibrium configuration, the modal analysis is followed. Consequently, the dead load effect to the stiffness can be included in the modal analysis. The modal analysis is therefore a "pre-stressed" modal analysis. Hence, the modal analysis of a suspension bridge must include two steps: static analysis due to dead load and "prestressed" modal analysis. For a completed suspension bridge, the initial position of the cable and 
bridge is unknown. Only the final geometry of the bridge due to the dead load is known. The initial geometry of the ideal finite element model of a suspension bridge should be such that the geometry of a bridge does not change when a dead load is applied, since this is indeed the final geometry of the bridge as it stands today. Besides, no forces should be induced in the stiffening structure. In other words, the deformed configuration of the bridge under the self-weight dead load should be close to the initial geometry input. This is approximately realized by manipulating the initial tension force in the main cables that is specified as an input quantity (prestrain) in the cable elements. The initial tension in the cables is achieved by trial until a value is found that leads to the minimum deflections and the minimum stresses in the stiffening structure due to dead load. In addition, the geometric nonlinear effect has been studied by including the stress stiffening and large deflection. All possible frequencies and mode shapes can be provided performing the prestressed modal analysis [7].

To determine the undamped free vibration mode shapes and frequencies of the system, load dependent Ritz-vector analysis is fast and more accurate as compared to the exact eigen function method. The modal analysis conducted in this thesis is based upon the stiffness at the end of a nonlinear static analysis for evaluation of the modes under P-delta large displacement effects [9]. Time history analysis of the bridge with different deck properties: With all properties remain same, only changing the deck properties (materials and sections), and the time history analysis shows the behavior of the bridge. SAP2000 software was used to analyze the structure.

\subsection{Analysis}

From the analysis, it was found that the behavior of the bridge changes drastically due to the modification of the deck properties by inserting the steel deck lay over stringer beam instead of the originally laid timber deck. The observed parameters were the deflection, axial tension in the suspension cable and moment and compressive stress in the pylon. The parameters were checked for no load condition and moving load condition. The moving load condition is analyzed by time history analysis [6].

Originally, the deflection observed was $815 \mathrm{~mm}$ downward deflection due to the self-weight (Fig. 6) of the bridge which came to stable configuration when prestress in the form of compressive restrain of magnitude $0.2607 \%$ was applied by successive trials (Fig. 7 ).

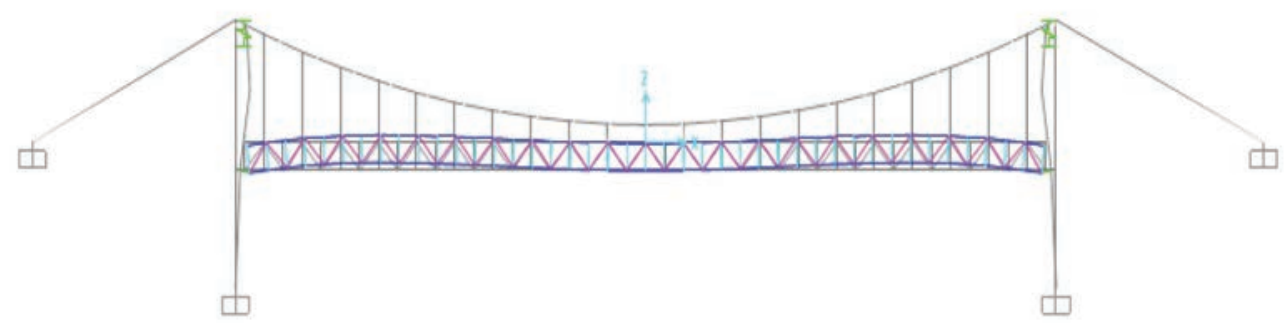

Fig. 6: Observed deflection in the bridge due to self-weight

On moving load analysis (Fig. 8) considering IRC 70R vehicle, the deflection is $172 \mathrm{~mm}$ downward. After replacement of the deck with steel plate, with no change in cable prestrain, the deflection found to be $170 \mathrm{~mm}$ upward at the center on the absence of vehicle movement. When the IRC 70R vehicle moves the variation in deflection is 170 to $27 \mathrm{~mm}$ upward, i.e. the variation in deflection 
during the vehicle movement found to be $143 \mathrm{~mm}$. The summary of deflection at the mid span is shown in Table 4.

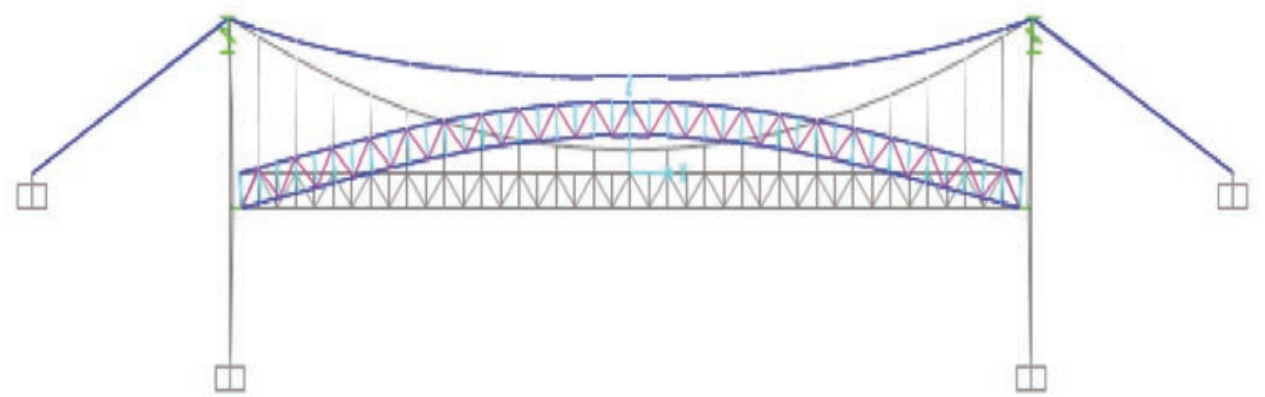

Fig. 7: Deflection observed after placement of Steel Deck with original compressive prestrain of $0.2607 \%$

Table 4: Deflection at mid span, $\mathrm{mm}$

\begin{tabular}{|c|c|c|}
\hline Load & Timber Deck & Steel Deck \\
\hline Dead Load & -0.0099 & +170.1551 \\
\hline Dead Load+ IRC 70R & -171.7686 & +27.0071 \\
\hline Variation & 171.7587 & 143.148 \\
\hline
\end{tabular}

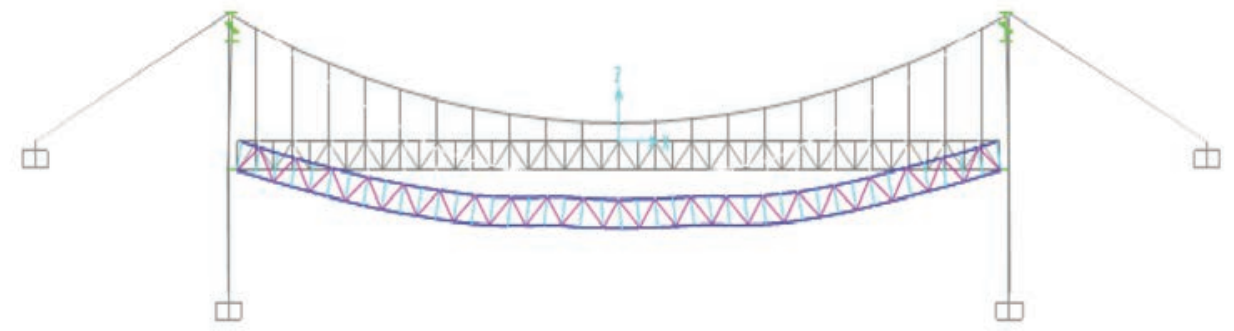

Fig. 8: Observed deflection in the bridge during IRC 70R vehicle movement

The dynamic behaviors of the bridge vary according to the deck properties as shown in Table 5 and Table 6 below.

Table 5: Modal Analysis Result (Timber Deck)

\begin{tabular}{|r|r|r|r|r|l|}
\hline \multirow{2}{*}{ Modal No. } & \multicolumn{1}{c|}{ Period } & \multicolumn{2}{c|}{ Modal Participating Mass Ratios } & \multirow{2}{*}{ Remarks } \\
\cline { 2 - 5 } & Sec & UX & UY & UZ & \\
\hline 1 & 15.589 & $0.00 \%$ & $13.32 \%$ & $0.00 \%$ & Cable \\
2 & 15.569 & $0.00 \%$ & $0.00 \%$ & $0.00 \%$ & Cable \\
3 & 14.9756 & $0.00 \%$ & $0.00 \%$ & $0.00 \%$ & Cable \\
12 & 4.5341 & $0.00 \%$ & $0.00 \%$ & $0.00 \%$ & Cable \\
13 & 3.5523 & $0.00 \%$ & $0.28 \%$ & $0.00 \%$ & Cable \\
14 & 3.5518 & $0.00 \%$ & $0.00 \%$ & $0.00 \%$ & Cable \\
\hline
\end{tabular}




\begin{tabular}{|c|c|c|c|c|c|}
\hline 19 & 2.2118 & $0.00 \%$ & $0.00 \%$ & $50.58 \%$ & Vertical \\
\hline 20 & 1.8991 & $0.00 \%$ & $0.00 \%$ & $0.00 \%$ & Cable \\
\hline 21 & 1.899 & $0.00 \%$ & $0.00 \%$ & $0.00 \%$ & Cable \\
\hline 22 & 1.8469 & $0.00 \%$ & $39.31 \%$ & $0.00 \%$ & Lateral \\
\hline 23 & 1.5943 & $0.00 \%$ & $0.20 \%$ & $0.00 \%$ & Cable \\
\hline 24 & 1.5942 & $0.00 \%$ & $0.00 \%$ & $0.00 \%$ & Cable \\
\hline 25 & 1.5907 & $0.04 \%$ & $0.00 \%$ & $0.00 \%$ & Vertical \\
\hline 26 & 1.3589 & $0.00 \%$ & $0.00 \%$ & $0.00 \%$ & Cable \\
\hline 33 & 0.9152 & $0.00 \%$ & $0.00 \%$ & $0.00 \%$ & Cable \\
\hline 34 & 0.8568 & $0.00 \%$ & $0.05 \%$ & $0.00 \%$ & Torsion \\
\hline 39 & 0.721 & $0.35 \%$ & $0.00 \%$ & $7.98 \%$ & Vertical \\
\hline 41 & 0.7106 & $81.66 \%$ & $0.00 \%$ & $0.04 \%$ & Cable \\
\hline 49 & 0.6309 & $0.00 \%$ & $0.00 \%$ & $0.00 \%$ & Cable \\
\hline 50 & 0.5161 & $0.00 \%$ & $0.00 \%$ & $0.00 \%$ & Torsion \\
\hline 51 & 0.4666 & $6.45 \%$ & $0.00 \%$ & $0.00 \%$ & Torsion \\
\hline 52 & 0.4205 & $0.00 \%$ & $7.79 \%$ & $0.00 \%$ & Torsion \\
\hline 53 & 0.3944 & $10.44 \%$ & $0.00 \%$ & $0.00 \%$ & Vertical \\
\hline 54 & 0.3592 & $0.00 \%$ & $0.00 \%$ & $0.00 \%$ & Lateral \\
\hline 55 & 0.3294 & $0.00 \%$ & $0.00 \%$ & $2.49 \%$ & Longitudinal \\
\hline 56 & 0.3217 & $0.00 \%$ & $1.57 \%$ & $0.00 \%$ & Torsion \\
\hline 57 & 0.3011 & $0.00 \%$ & $0.01 \%$ & $0.00 \%$ & Longitudinal \\
\hline 61 & 0.2475 & $0.00 \%$ & $2.66 \%$ & $0.00 \%$ & Cable \\
\hline 62 & 0.2331 & $0.00 \%$ & $0.00 \%$ & $1.18 \%$ & Cable \\
\hline 68 & 0.2167 & $0.00 \%$ & $0.42 \%$ & $0.00 \%$ & Lateral \\
\hline 72 & 0.2094 & $0.00 \%$ & $0.00 \%$ & $0.00 \%$ & Cable \\
\hline 73 & 0.2007 & $0.00 \%$ & $0.00 \%$ & $0.00 \%$ & Lateral \\
\hline
\end{tabular}

Table 6: Modal Analysis Result (Steel Deck)

\begin{tabular}{|r|r|r|r|r|l|}
\hline \multirow{2}{*}{ Modal No. } & \multicolumn{1}{c}{ Period } & \multicolumn{2}{c|}{ Modal Participating Mass Ratios } & \multirow{2}{*}{ Remarks } \\
\cline { 2 - 5 } & \multicolumn{1}{c|}{ Sec } & UX & UY & \multicolumn{1}{l|}{ UZ } & \\
\hline 1 & 15.5833 & $0.00 \%$ & $20.86 \%$ & $0.00 \%$ & Cable \\
2 & 15.569 & $0.00 \%$ & $0.00 \%$ & $0.00 \%$ & Cable \\
3 & 14.974 & $0.00 \%$ & $0.00 \%$ & $0.00 \%$ & Cable \\
12 & 4.5341 & $0.00 \%$ & $0.00 \%$ & $0.00 \%$ & Cable \\
13 & 3.5521 & $0.00 \%$ & $0.51 \%$ & $0.00 \%$ & Cable
\end{tabular}




\begin{tabular}{|c|c|c|c|c|c|}
\hline 14 & 3.5518 & $0.00 \%$ & $0.00 \%$ & $0.00 \%$ & Cable \\
\hline 22 & 1.5942 & $0.00 \%$ & $0.00 \%$ & $0.00 \%$ & Cable \\
\hline 23 & 1.3986 & $0.00 \%$ & $0.00 \%$ & $35.03 \%$ & Vertical \\
\hline 24 & 1.3589 & $0.00 \%$ & $0.00 \%$ & $0.00 \%$ & Cable \\
\hline 28 & 1.0297 & $0.00 \%$ & $0.00 \%$ & $0.00 \%$ & Cable \\
\hline 29 & 1.0297 & $0.00 \%$ & $0.00 \%$ & $0.00 \%$ & Cable \\
\hline 30 & 0.9505 & $1.13 \%$ & $0.00 \%$ & $0.00 \%$ & Vertical \\
\hline 31 & 0.9152 & $0.00 \%$ & $0.26 \%$ & $0.00 \%$ & Cable \\
\hline 32 & 0.9152 & $0.00 \%$ & $0.00 \%$ & $0.00 \%$ & Cable \\
\hline 33 & 0.8256 & $0.00 \%$ & $0.00 \%$ & $0.00 \%$ & Cable \\
\hline 34 & 0.8255 & $0.00 \%$ & $0.00 \%$ & $0.00 \%$ & Cable \\
\hline 35 & 0.8054 & $0.00 \%$ & $11.87 \%$ & $0.00 \%$ & Lateral \\
\hline 40 & 0.6902 & $0.00 \%$ & $3.97 \%$ & $0.00 \%$ & Torsion \\
\hline 41 & 0.6845 & $0.00 \%$ & $0.00 \%$ & $0.00 \%$ & Cable \\
\hline 48 & 0.4666 & $0.00 \%$ & $0.00 \%$ & $0.00 \%$ & Torsion \\
\hline 49 & 0.4616 & $0.00 \%$ & $0.00 \%$ & $5.54 \%$ & Vertical \\
\hline 50 & 0.3747 & $2.63 \%$ & $0.00 \%$ & $0.00 \%$ & Longitudinal \\
\hline 51 & 0.3466 & $0.00 \%$ & $0.00 \%$ & $0.00 \%$ & Torsion \\
\hline 52 & 0.3012 & $0.00 \%$ & $0.00 \%$ & $0.00 \%$ & Torsion \\
\hline 53 & 0.3005 & $0.08 \%$ & $0.00 \%$ & $0.00 \%$ & Torsion \\
\hline 54 & 0.2795 & $0.00 \%$ & $0.01 \%$ & $0.00 \%$ & Cable \\
\hline 55 & 0.2559 & $0.00 \%$ & $0.00 \%$ & $1.26 \%$ & Vertical \\
\hline 56 & 0.2415 & $0.00 \%$ & $0.01 \%$ & $0.00 \%$ & Torsion \\
\hline 57 & 0.2359 & $0.00 \%$ & $0.00 \%$ & $0.82 \%$ & lateral \\
\hline 58 & 0.2319 & $0.00 \%$ & $0.14 \%$ & $0.00 \%$ & Vertical \\
\hline 59 & 0.2286 & $0.00 \%$ & $0.00 \%$ & $0.00 \%$ & Longitudinal \\
\hline 60 & 0.2243 & $0.00 \%$ & $0.00 \%$ & $0.00 \%$ & Torsion \\
\hline
\end{tabular}

The dynamic behavior of the bridge in Timber Deck and Steel Deck is shown in Fig. 9 and Fig. 10 respectively. In Fig. 9 and Fig. 10, joint 301 is at the center of span, joint 251 is at the quarter of span and joint 196 is at the end of span. 


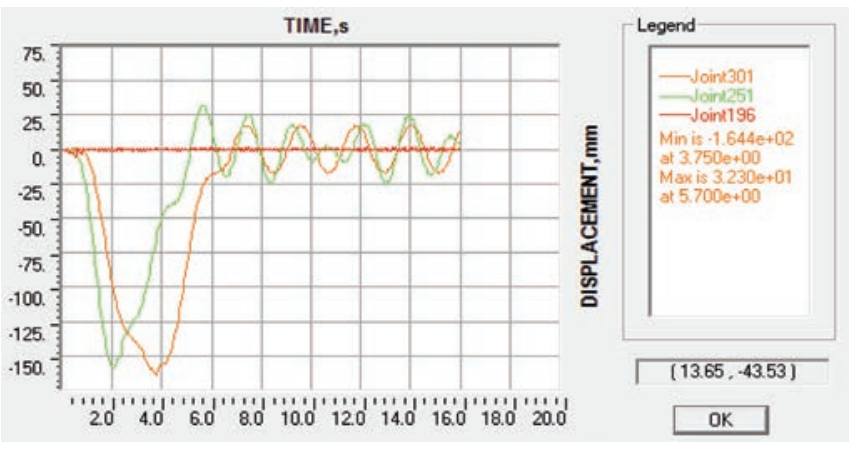

Fig. 9: Vibration in Timber Deck

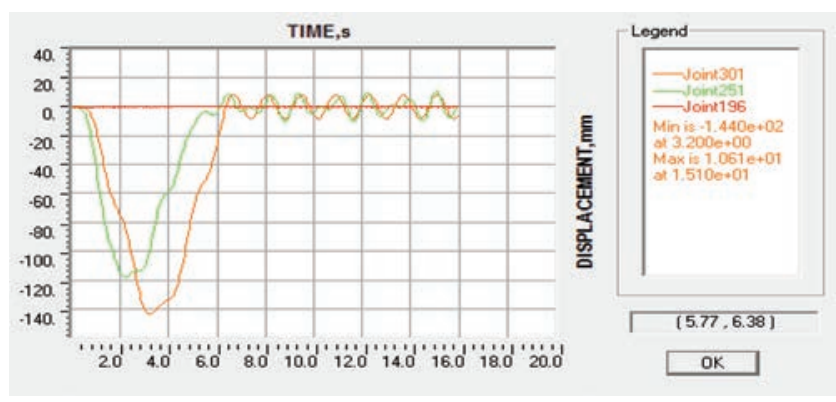

Fig. 10: Vibration in Steel Deck

\subsection{Results}

The deflection at the center of the bridge varies according to the self-weight of the bridge deck material and the strain applied: At no strain, deflection at center in for Timber Deck is $814.708 \mathrm{~mm}$ downward whereas for Steel Deck is $583.703 \mathrm{~mm}$ downward. Similarly, with Strain of $0.2607 \%$, deflection at center for Timber Deck is $0.0099 \mathrm{~mm}$ upward whereas for Steel Deck is 171.7686 $\mathrm{mm}$ upward. The difference in deflection at the centre of span at no strain case is $231.001 \mathrm{~mm}$ and with strain is $171.7587 \mathrm{~mm}$. The difference in no strain case and with strain case is due to the nonlinearity effect of the cable.

The modal properties represent the possible motion characteristics of the structure. From Table 5 and Table 6 , the frequency of the first vertical mode in the timber deck bridge is only 0.45147 which is too low as compared to the steel deck bridge 0.71489 and also the time period in the timber deck bridge is $2.2118 \mathrm{~s}$ which is more than 1.5 times greater than that in the steel deck bridge, 1.3986s. In overall, the frequency is higher in the case of steel deck than in the timber deck.

The time history analysis in the timber deck and steel deck shows that the vibration in the support, however it is of very less magnitude. The frequency of vibration in the steel deck is more than in the timber deck. At quarter span, the point goes down as vehicle enter to the bridge and maximum deflect at $2 \mathrm{~s}(160 \mathrm{~mm}$ in timber deck and $120 \mathrm{~mm}$ in steel deck), then rises. After 6 seconds, vibration is seen with amplitude nearly constant magnitude ( $40 \mathrm{~mm}$ in timber deck and $25 \mathrm{~mm}$ in steel deck). At center of the span, the point goes down as vehicle enter to the bridge and maximum deflect at $3.8 \mathrm{~s}(165 \mathrm{~mm}$ in timber deck and $145 \mathrm{~mm}$ in steel deck), then rises. Then, after 7 seconds, vibration is seen with amplitude constant magnitude ( $40 \mathrm{~mm}$ in timber deck and $20 \mathrm{~mm}$ in steel deck). The 
time history analysis when the left bearing removed in the steel deck shows that there is frequent vibration at all points. The vibration of the bridge is studied at different location of the span of the bridge at vehicle speed $10 \mathrm{kmph}$ and $36 \mathrm{kmph}$ as below.

At vehicle speed $2.78 \mathrm{~m} / \mathrm{s}(\mathbf{1 0} \mathrm{kmph})$ : Vibration at Left End: there is no vibration and only the left end goes down till 6 seconds, after 6 second, vibration begins with amplitude $280 \mathrm{~mm}$ for next 4seconds, then with amplitude of almost $980 \mathrm{~mm}$.

Vibration at Quarter Span: there is no vibration and only the point goes down till 6 seconds, after 6 second, vibration begins with amplitude $230 \mathrm{~mm}$ for next 4 seconds, then with amplitude of almost $980 \mathrm{~mm}$.

Vibration at 45m from Left End: there is no vibration and only the left end goes down till 6 seconds, after 6 second, vibration begins with amplitude $60 \mathrm{~mm}$ for next 4 seconds, then with amplitude of more than $200 \mathrm{~mm}$.

Vibration at Center of the Span: there is no vibration and only the point goes up till 6 seconds, after 6 second, vibration begins with amplitude $50 \mathrm{~mm}$ for next 4seconds, then with amplitude of varying magnitude of more than $180 \mathrm{~mm}$. The comparison of vibration at different location of the span is shown in Fig. 11.

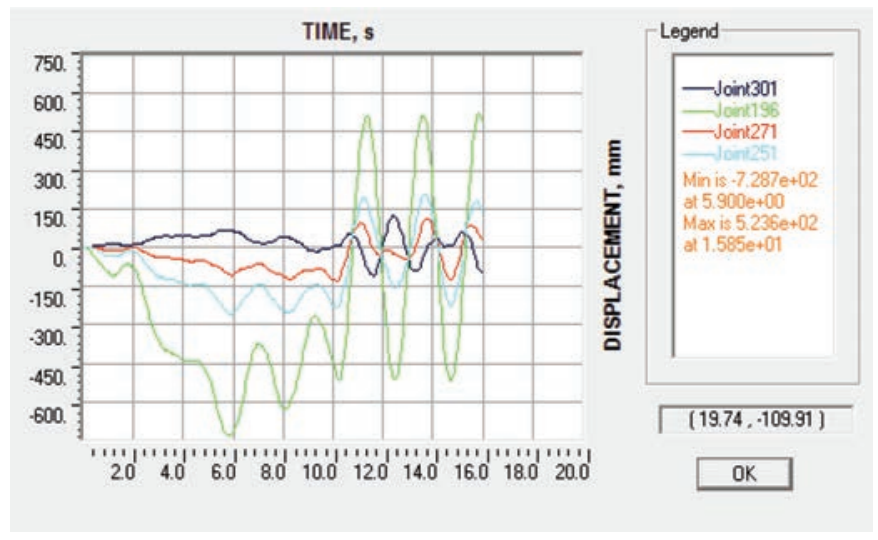

Fig. 11: Comparative Vibration at Different Points for Vehicle Speed of 10kmph

At vehicle speed 10m/s (36kmph): Vibration at Left End: there is vibration with amplitude $867 \mathrm{~mm}$ and goes down till 2 seconds and then with amplitude of almost $600 \mathrm{~mm}$ in every 2 seconds rises.

Vibration at Quarter Span: there is vibration with amplitude $250 \mathrm{~mm}$ and goes down in 2 seconds and then rises with amplitude of almost $275 \mathrm{~mm}$ in every 2 seconds.

Vibration at $45 \mathrm{~m}$ from Left End: the point goes down with amplitude of 140mm. After 6 seconds, it rises with amplitude $130 \mathrm{~mm}$. After 11 seconds the amplitude of constant magnitude $100 \mathrm{~mm}$.

Vibration at Center of the Span: the point vibrates with amplitude $150 \mathrm{~mm}$ and goes down till 8 seconds and then increases first with amplitude $180 \mathrm{~mm}$ and then decreases. Hence, with high speed, vibration at all points starts immediately with nearly constant amplitude while with low speed, vibration starts after some time at all points and goes on increasing. The comparison of vibration at different location of the span is shown in Fig. 12 at this speed. 


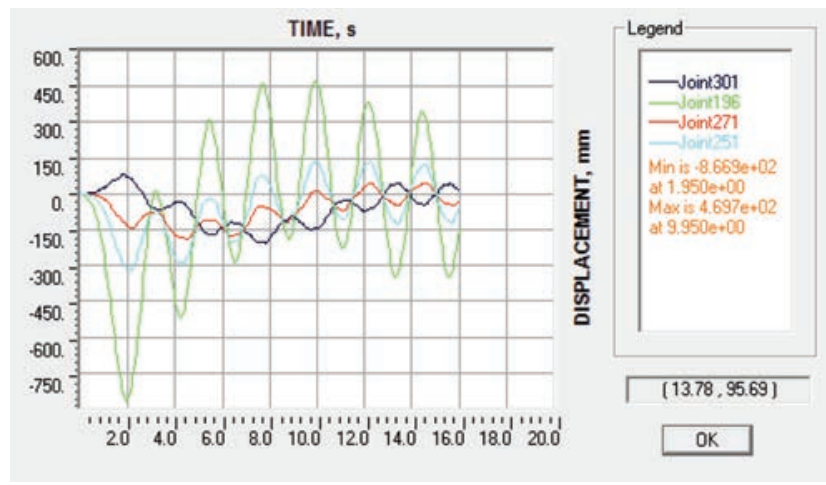

Fig. 12: Comparative Vibration at Different Points for Vehicle Speed of 36kmph

\section{Conclusion}

In this study, the change in behavior of the motorable suspension bridge due to modification in deck properties is studied using 3-dimensional finite element analysis. Suspension bridge being a prestressed, the replacement of thick timber deck with thin steel plate, though reduces the weight, has changed the response of the bridge significantly which subsequently affected the traffic and also caused the drastic change in the stresses in the girder frames and at the nut-bolts and rivets leading to the failures of bearing at the supports. It is concluded and recommended to increase mass of deck material and replacement of bearings for better performance of the bridge. The deck weight can be increased by addition of thick asphalt concrete.

\section{References}

[1] Abdel-Ghaffar AM (1982), Suspension bridge vibration: continuum formulation, Journal of the Structural Division, ASCE, 108 (6) : 1215-1232.

[2] Buonopane SG (2012), A historical perspective on suspension bridges: Design vs. Analysis and the work of John A. Roebling, in Hines, E. M., Buonopane, S. G. and Garlock, M. E. M. (Editors), Festchrift Billington, 2012: Essays in Honour of David P Billington, International Network for Structural Art.

[3] Cook R (1995), Finite element modeling for stress analysis. John Wiley \& Sons, Inc., Toronto.

[4] Daibagya MR (2014), Effect of modification of deck properties on suspension bridge response under moving loads: A Case Study of Mungling Bridge. Department of Civil Engineering, Pulchowk Campus, Institute of Engineering, Tribhuvan University, Nepal.

[5] Gimsing NJ (2012). Cable supported bridges - concept and design, 3rd edition. Chichester: John Wiley \& Sons Ltd.

[6] Hayashikawa T and Watanabe N (1982), Suspension bridges response to moving loads, Journal of the Structural Division, ASCE, 108(6) : 1051-1066.

[7] Ren WX, Huang MG and Hu WH (2008), A parabolic cable element for static analysis of cable structures. Engineering Computations, 25(4) : 366-384.

[8] Westgate RJ (2012), Environmental Effects on a Suspension Bridge's Performance. Department of Civil and Structural Engineering, University of Sheffield, UK.

[9] Wilson EL (1995), Three-dimensional static and dynamic analysis of structures: a physical approach with emphasis on earthquake engineering. Computers \& Structures Inc., Berkeley, California, US. 